Revue de l'Institut des langues et cultures

d'Europe, Amérique, Afrique, Asie et Australie

$35 \mid 2019$

Intermédialités dans les arts et la littérature de l'Espagne $\left(X X^{e}\right.$ et $X X I^{e}$ siècles)

\title{
La narrativa expandida de Jorge Carrión y Agustín Fernández Mallo: prácticas intermediales en la época postdigital
}

L'expansion narrative dans les cuvres mutantes de Jorge Carrión et Agustín Fernández Mallo : les pratiques intermédiales à l'époque postnumérique The Expanded Narrative of Mutant Writers Jorge Carrión and Agustín Fernández Mallo: Intermedial Practices in the Postdigital Era

\section{Roxana llasca}

\section{OpenEdition}

\section{Journals}

Edición electrónica

URL: http://journals.openedition.org/ilcea/6171

DOI: 10.4000/ilcea.6171

ISSN: 2101-0609

Editor

UGA Éditions/Université Grenoble Alpes

Edición impresa

ISBN: 978-2-37747-083-9

ISSN: 1639-6073

\section{Referencia electrónica}

Roxana Ilasca, «La narrativa expandida de Jorge Carrión y Agustín Fernández Mallo: prácticas intermediales en la época postdigital », ILCEA [En línea], 35 | 2019, Publicado el 27 marzo 2019, consultado el 19 mayo 2020. URL : http://journals.openedition.org/ilcea/6171 ; DOI : https://doi.org/ 10.4000/ilcea.6171

Este documento fue generado automáticamente el 19 mayo 2020

(C) ILCEA 


\title{
La narrativa expandida de Jorge Carrión y Agustín Fernández Mallo: prácticas intermediales en la época postdigital
}

\author{
L'expansion narrative dans les cuvres mutantes de Jorge Carrión et Agustín \\ Fernández Mallo : les pratiques intermédiales à l'époque postnumérique \\ The Expanded Narrative of Mutant Writers Jorge Carrión and Agustín Fernández \\ Mallo: Intermedial Practices in the Postdigital Era
}

\section{Roxana Ilasca}

La hibridación o encuentro de dos medios es un momento de la verdad y de revelación del que surgen nuevas formas. El paralelismo entre dos medios nos mantiene en las fronteras de las

formas que nos despiertan de la NarcirsoNarcosis. El encuentro de varios medios es un momento de libertad, de liberación del trance ordinario y del entumecimiento de los sentidos.

Marshall McLuhan, Comprender los medios de comunicación

1 A principios del siglo xxI surge, en el ámbito cultural español, un movimiento literario que algunos denominan «Nocilla», otros «mutante», «pangeico» o «afterpop». Se califica a los autores asociados a este fenómeno literario-Jorge Carrión, Agustín Fernández Mallo, Eloy Fernández Porta, Juan Francisco Ferré, Robert Juan-Cantavella, Vicente Luis Mora, Germán Sierra, etc.- como figuras representativas de una nueva narrativa. Estos escritores se proponen sentar las bases de una poética a su vez en mutación, al producir obras singulares, que muestran los cambios culturales producidos en la época contemporánea. Las nuevas tecnologías y los medios de comunicación más recientes producen unas transformaciones incontestables en el 
proceso de creación. El autor aboga por una obra que se extiende más allá de los límites del texto escrito, hacia otras plataformas, lenguajes y medios.

2 En este artículo, me detendré en los textos de dos escritores mutantes, Jorge Carrión y Agustín Fernández Mallo, para analizar distintas técnicas intermediales en la literatura española actual. Se tratará, pues, de observar el modo en que se construye la obra al intersecarse con otros medios de comunicación y producción cultural, en este periodo de expansión e hibridación narrativa que Germán Sierra califica de «postdigital». La intermedialidad no es, evidentemente, un fenómeno nuevo o reciente; sin embargo, es incuestionable que los medios tienen un papel cada vez más significativo en el proceso de creación contemporánea y sobre todo en las obras mutantes que se presentarán aquí. La integración de varios medios como parte constitutiva de una forma literaria híbrida, expandida, pero unitaria, es patente en proyectos narrativos como la trilogía «Nocilla» de Agustín Fernández Mallo o la tetralogía «Las huellas» de Jorge Carrión, que integran varios lenguajes: la fotografía, el dibujo, el video, la banda sonora, el post de blog, el guion cinematográfico, etc. La obra mutante se sirve de la habitual tensión entre la palabra y otros modos de expresión artística a fin de cuestionar las formas literarias hoy en día. El lector -al que Vicente Luis Mora llama «lectoespectador» en este contexto de hibridación mediática ${ }^{1}$ - debe decidir si está dispuesto a prolongar su experiencia de lectura, para recorrer el texto en su totalidad:

El lectoespectador tiene que tomar una decisión sobre qué considera legible en la novela; cada quien debe decidir hasta dónde llega su participación a la hora de seguir los vínculos, acudir a los otros soportes, o considerar como texto las partes visuales. (Mora, 2012: 114)

3 El porvenir del texto literario es híbrido y las ideas desarrolladas en este trabajo mostrarán que, en la narrativa mutante, la intermedialidad no supone la preeminencia de un medio sobre otro, sino la iniciación de una dinámica creativa que genera la interacción entre los distintos medios de difusión y modos de expresión. En vez de buscar a imponerse sobre las demás formas de expresión artística, las estructuras narrativas híbridas fomentan el diálogo entre las artes y los medios.

4 Calificaré la obra que integra varios lenguajes y soportes mediáticos de «literatura expandida $»^{2}$, para designar una práctica de escritura que disemina su contenido narrativo en lenguajes, soportes y medios diferentes. Dada la proliferación de las nociones relacionadas con la interacción de los medios -transmedia, cross-media, multimedia remediation, etc.-parece más adecuado optar por este término más amplio -y menos connotado desde el punto de vista teórico- de literatura expandida, para denominar las técnicas de correlación mediática en las obras mutantes.

5 Al practicar la hibridación, es decir la mezcla de escritura literaria y distintos lenguajes mediáticos, la obra mutante busca crear puentes entre la creación y los dispositivos técnicos actuales. Es patente que el mundo contemporáneo, con sus modos y medios de expresión e información, se expande a través de los medios que comunican entre sí, se cruzan y pasan de un soporte al otro. La integración de tales herramientas en la obra narrativa de estos autores produce un cambio de enfoque: en vez de concentrarse en la posible rivalidad o competencia entre los modos de producción artística, se destaca precisamente el potencial creativo y expresivo del medio para dar forma a una nueva estética, más apropiada a la realidad tecnológica del siglo xxI.

Así pues, se tratará de exponer, en este artículo, las diferentes estrategias o técnicas que emplean los mutantes Jorge Carrión y Agustín Fernández Mallo para integrar otros 
lenguajes mediáticos en sus obras. Más particularmente, habrá que observar cómo manipulan ambos autores los elementos visuales en el proceso de creación, en una época en que se ha dado lo que Gottfried Boehl ${ }^{3}$ llama the iconic turn, es decir el paso de las artes visuales a las imágenes ${ }^{4}$. En Nocilla Lab, Agustín Fernández Mallo emplea el medio televisivo para desviar su uso habitual y concederle un valor artístico. Además, el ilustrador Pere Joan transpone el segundo libro de la trilogía «Nocilla» en otro lenguaje, al crear Nocilla Experience. La novela gráfica (2011), que enriquece el texto original con esta nueva versión y, al mismo tiempo, pone en tela de juicio las fronteras de la obra narrativa, estrechamente vinculada con su adaptación gráfica. La misma complementariedad del texto y la imagen se nota en el relato Los difuntos de Jorge Carrión (2015a), gracias a la colaboración con el dibujante Celsius Pictor. El autor del proyecto «Las huellas» alude también, a través de su reflexión sobre la imagen en el siglo xxI, a la creación cinematográfica-como se mostrará en la quinta parte de este estudio-e implícitamente al desarrollo técnico-la máquina-que permite la grabación de imágenes.

7 El cuestionamiento de la relación entre la creación artística y la máquina (cinematográfica o literaria) tendrá un impacto sobre la concepción del proceso de escritura, que convierte la herramienta mediática en instrumento narrativo o artístico. Esta mutación del dispositivo técnico en la obra es típica de la literatura postdigital, como se indicará en la segunda sección de este trabajo.

8 Sin embargo, antes de analizar las obras mismas, habrá que detenerse rápidamente en el fenómeno de hibridación mediática, que se asociará, en el presente artículo, al concepto de convergencia cultural, acuñado por el especialista de los medios de comunicación Henry Jenkins. El término nos permitirá entender mejor la técnica postpoética de Agustín Fernández Mallo como proceso de convergencia de varios objetos mediáticos, del libro al espectáculo spoken work.

\section{La intermedialidad postpoética de Agustín Fernández Mallo como forma de convergencia cultural}

9 En 1965, el artista Dick Higgins califica de intermedia ciertas prácticas que introducen objetos -o medios- ajenos en la obra de arte. En la misma época, surgen, en el ámbito literario conceptos como la intertextualidad y la transtextualidad, que tienen como fundamento el principio de mezcla de lenguajes distintos (Fischer, 2015: 9-10). A pesar de esta base estética, el estudio de la intermedialidad incumbirá finalmente a las ciencias de la comunicación y no a la teoría literaria o a las artes. Actualmente, a principios del nuevo siglo, esta práctica ya no puede restringirse a un área u otra, puesto que la correlación de los medios es un fenómeno central de toda producción cultural.

10 Como ya lo han apuntado los teóricos de los medios, la hibridación mediática es consecuencia de la convergencia cultural que caracteriza la época contemporánea. Jenkins define esta noción central de la manera siguiente:

Con «convergencia» me refiero al flujo de contenido a través de múltiples plataformas mediáticas, la cooperación entre múltiples industrias mediáticas y el comportamiento migratorio de las audiencias mediáticas, dispuestas a ir casi a cualquier parte en busca del tipo deseado de experiencias de entretenimiento; la palabra describe los cambios tecnológicos, industriales, culturales y sociales en 
función de quienes hablen y de aquello a lo que crean estar refiriéndose. (Jenkins, 2008 [2006]: 14) decir una migración hacia un dispositivo único que sería capaz de almacenar todos los medios y convertir así los otros soportes en objetos inútiles u obsoletos: «Antes bien, la convergencia representa un cambio cultural, toda vez que se anima a los consumidores a buscar nueva información y establecer conexiones entre contenidos mediáticos dispersos» (Jenkins, 2008 [2006]: 15). En otras palabras, la convergencia no es el resultado del desarrollo tecnológico, sino de los procesos mentales del lector o consumidor de productos culturales, cuyo cerebro conecta, en una dinámica intermedial, las piezas diseminadas en varios soportes. Así pues, para Henry Jenkins, el proceso de convergencia consiste en establecer vínculos entre las experiencias culturales que proporcionan las diferentes herramientas mediáticas. Por tanto, la convergencia es «a paradigm for thinking about the current moment of media change, one which is defined through the layering, diversification, and interconnectivity of media» (Jenkins, 2011). La convergencia se manifiesta a través de la sinergia de una gran variedad de formas mediáticas que, en vez de sustituirse las unas a las otras, actúan de manera complementaria en la mente del individuo (Jenkins, 2007). Agustín Fernández Mallo, podrían movilizarse los términos «intermedialidad» y «convergencia cultural» para analizar la correlación de la escritura con las artes visuales en el proyecto «Nocilla». Desde esta perspectiva, tanto el medio metraje dirigido por el autor como su ensayo Postpoesía (Anagrama, 2009), o incluso el proyecto spoken word para el cual colabora con el ensayista y crítico cultural Eloy Fernández Porta, completan la lectura de la trilogía, gracias a la interconectividad de todas estas piezas mediáticas. La película y el ensayo informan sobre el proceso de creación de la narrativa de Fernández Mallo y apoyan, al mismo tiempo, las observaciones teóricas con ejemplos de práctica postpoética, término que el escritor define como una visión plural-pluridisciplinaria, plurilingüe, apropiacionista-de la creación literaria. El autor de la trilogía «Nocilla» construye esas piezas complementarias con el objetivo de expandir su universo poético más allá de los límites de la palabra o la escritura, hacia otros soportes o dispositivos. Más aún, varios lenguajes se intersecan dentro de las obras mismas. El ensayo Postpoesía ensambla texto, imagen y fórmulas matemáticas o físicas y establece, así, conexiones inesperadas entre la postpoesía - la literatura, en un sentido más amplio-, la ciencia y las artes. Las imágenes, que abundan en este trabajo teórico - de la fotografía y la pintura a los gráficos-expanden la lectura hacia lo visual.

13 También en la película, se mezclan las reflexiones teóricas y las secuencias artísticas, como ejemplos concretos de la práctica postpoética. El video conjuga varios lenguajes mediáticos: grabaciones del propio escritor, entrevistas a artistas y autores, archivos de televisión, fotos, fragmentos del espectáculo spoken word «Afterpop: Fernández \& Fernández», secuencias a las que se les añade una banda sonora y los comentarios del propio autor. De esta forma, Fernández Mallo llama la atención sobre la tensión entre diferentes modos de expresión artística, entre la teoría y la práctica, entre la escritura y las artes visuales, a través de la técnica intermedial. En la sección siguiente, me concentraré en el lenguaje visual en la narrativa de Jorge Carrión y

ILCEA, 35 | 2019 
Agustín Fernández Mallo para luego poder analizar algunos ejemplos concretos de imágenes en sus obras.

\section{Hacia una imagen postdigital: la intermedialidad en el texto literario mutante}

Aunque no se trata de una técnica innovadora, el uso de la imagen en la obra mutante pasa por un proceso de actualización. La proliferación del contenido visual en la escritura literaria se explica por el hecho de que, hoy día, la cultura es esencialmente visual (Mora, 2012: 17). La narrativa ya no se construye con palabras, sino que es textovisual, según apunta el autor de Lectoespectador, es decir que su lectura supone recorrer tanto el texto impreso como las imágenes que lo acompañan. El propio Mora califica este formato de "pantpágina», al hablar de este proceso artístico de mutación de la página del libro en pantalla, lo que implica una comprensión y percepción de la obra a la vez textual y visual. Se trata de una práctica narrativa que explora las distintas posibilidades de interacción entre la escritura y los medios $-\mathrm{y}$, más particularmente, los formatos icónicos, como la fotografía o el grafismo-. A diferencia de los textos que, en los siglos anteriores, solo experimentaban con la imagen plástica, la pantpágina elabora su propia estructura visual a partir del modelo de los nuevos medios, que integran casi exclusivamente la pantalla (Mora, 2012: 105-114).

Por lo tanto, en el siglo xxI, el texto ya no puede prescindir de la imagen si quiere (re)presentar -y cuestionar- la realidad de la que surge. No obstante, el hecho de recurrir a esta técnica narrativa no es una mera estrategia de ilustración o traducción del texto a otro lenguaje. Lo visual crea más bien una tensión con la escritura, al hacerse eco de la realidad mediática en la que el propio lector se ve sumergido.

Serge Bouchardon apunta que esta relación entre los medios fundamenta la tecnología digital, que aumenta las posibilidades de «intersemiotización», es decir «la façon dont ces médias font signe et sens entre eux» (Bouchardon, 2014: 52). Para el autor, se trata de un proceso de escritura ${ }^{5}$ que entabla la transformación o mutación de los medios tradicionales y sobre todo de sus "caractéristiques sémiotiques culturellement héritées» (Bouchardon, 2014: 53). La imagen que se convierte o se traduce en otro lenguaje adquiere nuevos significados, según se verá en las secciones siguientes. Así pues, si para Bouchardon la intersemiotización es un rasgo característico de la literatura digital, hay que subrayar que este proceso no se limita a las creaciones en formato electrónico, sino que se extiende a las obras impresas, que ponen en tela de juicio «la frontière entre le visible et le lisible» (Bouchardon, 2014: 53). De la imagen fotográfica o catódica a la imagen digital y, luego, en sentido contrario, de lo digital a lo analógico -o sea al texto impreso-, el elemento visual se deja impregnar por los medios que le sirven de soporte.

17 En la trilogía «Nocilla» de Agustín Fernández Mallo, la imagen que toma varias formas-croquis, cómic, reproducción, manipulación digital de fotografías o fotogramas de televisión-desempeña papeles muy diferentes. Si Nocilla Dream (Candaya, 2006) se cierra con una representación cartográfica de su universo narrativo ${ }^{6}$, las últimas páginas de Nocilla Lab (2009) son textovisuales, al convertirse en cómic. Además, la tercera parte de la trilogía integra varias imágenes - por ejemplo, una serie de fotogramas de programas de televisión, según lo apunta el narrador de la 
novela (Fernández Mallo, 2009: 129) -. Nocilla Experience (2008) adopta, sin embargo, otra técnica: aunque el libro mismo no contiene ninguna representación iconográfica, el texto en su conjunto se somete a un trabajo de traducción visual, a través de la adaptación gráfica de Pere Joan, el autor de Nocilla Experience. La novela gráfica (2011). En el presente estudio se establecerá una relación entre este trabajo de colaboración entre artistas, cuyo objetivo es la expansión de la experiencia lectora-de hecho, el autor del cómic que cierra la novela Nocilla Lab es también Pere Joan-, y el relato Los difuntos (2015a), como prueba de la contribución del ilustrador Celsius Pictor al proyecto de Jorge Carrión ${ }^{7}$. Hay que subrayar que, en esas obras, se impone el formato del libro impreso, pero con ciertas modificaciones o mutaciones, a menudo muy significativas. Se trata de textos que, sin dejar de preferir la escritura o el libro impreso, integran otros medios de expresión artística, al adoptar una estética que denominaré postdigital. Según la mayor parte de los teóricos que han estudiado el fenómeno, lo «postdigital» o «post-Internet»-surge a principios de los años 2000. Sin embargo, el artista Artie Vierkant apunta, en su propio estudio del concepto, que no hay que buscar una fecha o un acontecimiento en particular que haya anunciado los comienzos del periodo postInternet:

It would be antithetical to attempt to pinpoint any discrete moment at which the PostInternet period begins. Any cultural production which has been influenced by a network ideology falls under the rubric of Post-Internet. The term is therefore not discretely tied to a certain event, though it could be argued that the bulk of the cultural shifts [...] come with the introduction of privately-run commercial Internet service providers and the availability of personal computers. (Vierkant, 2010: 1)

19 El artista añade, más adelante, que, en el contexto post-Internet, la obra de arte consiste tanto en el objeto que se expone en un museo como en las imágenes u otras representaciones y reproducciones diseminadas en Internet o en diversos soportes analógicos, copias pirateadas, versiones que se apropian de los demás autores (Vierkant, 2010: 5). A partir de esta observación, hay que apuntar que la obra postInternet es, en realidad, una construcción intermedial que establece vínculos entre distintos dispositivos o formatos que contribuyen a su difusión. En su recorrido de una plataforma a otra, la creación postdigital abarca los mismos medios que participan en su diseminación.

Como apunta, a su vez, Florian Cramer, el fenómeno postdigital cobra forma cuando las nuevas tecnologías o nuevos medios dejan de ser una novedad, es decir en el momento en que las herramientas digitales se convierten en objetos de uso cotidiano:

"post-digital" phenomena [...] exemplify a new functional differentiation of publication forms after networked electronic devices have become objects of everyday use. Although the term "post-digital" is prone to misunderstanding and lacks terminological precision, it still usefully describes a contemporary critical revision of "new media". (Cramer, 2016: 23)

21 En otras palabras, la estética postdigital surge como posibilidad de superación de cierto efecto de moda de lo digital, que ha dominado el ámbito artístico estas últimas décadas. Así pues, el concepto busca abandonar la oposición analógico-digital, es decir la dicotomía antiguo-nuevo en lo que concierne las tecnologías y los medios contemporáneos. La visión postdigital invita, más bien, a aprovecharse de esas relaciones complejas, de dependencia, entre lo digital y lo analógica en el proceso de creación artística hoy en día (Cramer, 2016: 23). Tal actitud no excluye, sin embargo, cierto distanciamiento - no solo temporal, sino también crítico- al observar y analizar los medios. La descontextualización del medio, del ámbito de la comunicación e 
información al territorio de las artes, supone también poner en tela de juicio el dispositivo mismo.

En vez de buscar cierta «normalización» de la relación entre la creación artística y la tecnología mediática, la perspectiva postdigital supone la elaboración de una estética que trascienda su época, a través de la visión crítica sobre las técnicas no literarias. En el ámbito español, el escritor Germán Sierra reflexiona, a su vez, sobre el término postdigital en relación con la literatura contemporánea mutante, al llamar la atención sobre la necesidad de desarrollar un discurso crítico en cuanto a los fallos de la tecnología:

Cuando empleo el término postdigitalidad no me refiero en absoluto a que el arte digital esté siendo -o vaya a ser-relegado por novedades analógicas o, menos todavía, como algunos pensadores han pretendido, un regreso a la seguridad de «lo real» tras una pasajera fascinación por «lo virtual». Cultura postdigital es, en mi opinión, aquella que produce una sociedad que ha asimilado lo digital como parte del mundo «natural» [...], de tal modo que lo digital deja de ser el medio supremo de las artes o un objetivo artístico en sí mismo, se hibrida espontáneamente con lo analógico y, a partir de ese momento, hace volar por los aires la dualidad «analógico/digital». (Sierra, 2010: 11)

A diferencia de Cramer, que se centra en las artes visuales, Sierra moviliza en su trabajo sobre la estética postdigital el ejemplo del ámbito musical, a partir de las teorías del artista Kim Cascone, enunciadas a principios del nuevo siglo ${ }^{8}$. La música postdigital ya no se contenta con insertar la tecnología en el proceso de creación, sino que adopta una mirada crítica sobre ella, al incorporar sus fallos técnicos. Esta nueva estética llama la atención sobre el hecho de que los dispositivos técnicos son imperfectos, inexactos, a menudo ineficaces (Sierra, 2010: 11).

En otro artículo suyo sobre la literatura postdigital española, Sierra (2012: 24-25) decide asociar el concepto de fallo (en inglés, failure), que propone Cascone, con el uso del spam en la postpoesía de Agustín Fernández Mallo. El residuo y el material superfluo se reciclan en el proyecto «Nocilla» y adquieren una función estética al integrarse en el tejido narrativo de la obra postpoética. Se nota el mismo empleo del objeto imperfecto o defectuoso en las grabaciones low tech que el autor añade a su obra ${ }^{9}$. Las fotos y los videos son a menudo borrosos o pixelados. Se nota un rechazo constante de la alta definición o de la tecnología de última generación en su manipulación de la imagen. En una época en que la tendencia habitual es la optimización de los dispositivos, los autores que prefieren trabajar con tecnologías obsoletas muestran que la creación híbrida, intermedial, o sea postdigital, no requiere una constante actualización técnica, sino una actualización estética, en la que el uso de la herramienta tecnológica se desvía hacia fines artísticos.

En las siguientes secciones se observarán algunos ejemplos concretos de elementos visuales intermediales que emplean los autores mutantes Jorge Carrión y Agustín Fernández Mallo en sus obras.

\section{Tele-visión: intermedialidad del texto literario y de la imagen catódica en la obra postdigital}

En «Motor automático», la segunda parte de Nocilla Lab, el narrador encerrado en la antigua penitenciaría que sirve ahora de pensión de agroturismo emprende una 
experiencia artística que consiste en tomar fotos de la pantalla de su televisor en marcha:

Se me ocurrió retomar una práctica que años atrás me había entretenido: hacerle fotos a la tele. En otra época lo hacía con intereses exclusivamente artísticos, pero ahora mis intenciones eran otras: fijar en papel todo lo que pudiera parecerse a esa cárcel, a esa ignominiosa situación, dar fe de mi historia allí a base de fotografías extraídas del único lugar en el que en aquellos días existía vida, la pantalla de la tele, con la intención de que si algo me pasase alguien pudiera encontrarlo. (Fernández Mallo, 2009: 129)

Las fotografías que acompañan el texto llevan comentarios y explicaciones del narrador. Evidentemente, la tecnología catódica pasa por un proceso de mediación tanto visual como textual-, puesto que las imágenes son a menudo borrosas. El narrador aclara que su apropiación mediática se somete a dos principios: por un lado, se trata, por lo menos en el principio, de una experiencia artística y, por otro lado, se busca traducir el relato del personaje en su representación visual. El propio protagonista admite que se puede notar fácilmente una posible analogía entre su situación y las fotos seleccionadas, al llamar la atención sobre ciertos detalles visuales que remiten a su condición de recluso o a la separación de la pareja ${ }^{10}$.

A través del traslado de un leguaje a otro, el narrador llega a la conclusión de que no es simplemente un (tel)espectador, sino el objeto de estudio de otro, como si se hubiera dado cuenta, de repente, de su condición de personaje de ficción que se deja observar por el ojo escrutador del lectoespectador: «Me di cuenta de que en esa última foto yo ya estaba adherido, colado, en ese otro mundo inverso. $\mathrm{Y}$ es que, claramente, mi vida estaba siendo televisada. Me pregunté cuántos televidentes me estarían viendo» (Fernández Mallo, 2009: 134).

29 La obra postdigital utiliza la imagen para denunciar la posibilidad de que el lector se convierta en mero espectador de los productos icónicos que invaden su cotidianeidad y le propone al lectoespectador una lectura híbrida que no rechaza esta realidad. La televisión como medio consiste en transmisiones sucesivas de imágenes que no se detienen y no se dejan estudiar o analizar desde un punto de vista crítico. Sin embargo, al trasladarse a otra forma mediática, en el soporte «inmóvil» del objeto-libro, el medio televisivo se ve sometido al proceso de intersemiotización del que habla Bouchardon. La fotografía impresa sobre la página del libro se convierte en una imagen congelada, lo que le permite al lectoespectador observar detenidamente y, al mismo tiempo, buscar nuevos significados del contenido tanto visual como textual de la obra.

30 Como apunta Bouchardon, los medios digitales desempeñan un papel esencial en este proceso de construcción textovisual de la obra mutante, al fomentar las posibilidades técnicas de manipulación de los distintos materiales. Efectivamente, el formato electrónico es capaz de codificar todos los medios de la misma forma y mantener, a la vez, «les propriétés sémiotiques de ces différents médias» (Bouchardon, 2014: 227). Dentro de la obra intermedial, hay una influencia mutua de los distintos medios los unos sobre los otros: "[l]'image se parcourt parfois comme un texte qui articule un système d'indices et le texte se pare des attributs de l'image en mettant en avant une dimension iconique» (Bouchardon, 2014: 227-228).

31 Si en esta parte se ha estudiado cómo el uso de distintos lenguajes mediáticos - foto y televisión-en el proyecto «Nocilla» contribuye a la construcción de la figura del 
escritor como artista, en la sección siguiente habrá que observar los proyectos colaborativos entre escritores y artistas.

\section{Pluri-visión: intermedialidad del texto y de la ilustración gráfica en la obra postdigital}

La creación de proyectos intermediales supone a menudo la colaboración entre los artistas. Para estudiar este fenómeno, me concentraré en las obras mutantes Nocilla Experience de Agustín Fernández Mallo (2008), con su adaptación gráfica (Joan, 2011), y el relato Los difuntos, un trabajo común del escritor Jorge Carrión y el dibujante Celsius Pictor. Este análisis me permitirá observar el papel de la representación iconográfica en el texto mutante en la época postdigital. En cuanto a la segunda parte de la trilogía «Nocilla», se tratará de analizar, a partir de uno de los micro-capítulos de la obra de Fernández Mallo, el vínculo que se establece entre el texto y su traducción visual. Lo mismo se hará con Los difuntos, donde se mirarán los dibujos únicamente en relación con el relato que éstos acompañan.

Tomemos como ejemplo el tercer capítulo de la novela Nocilla Experience:

Sandra hace el vuelo Londres-Palma de Mallorca. Apenas 1 hora en la que el giro de la Tierra se congela. Hojea la revista British Airways News. Reportajes de vinos Ribeiro, Rioja, las últimas arquitecturas high-tech en Berlín, ventas por correo de perlas Majorica. Sobre una foto de una playa del Caribe le cae una lágrima, pero no por culpa de la playa, ni del Caribe, ni de la gravitación que les es propia a las lágrimas. Mira por la ventanilla, lleva los ojos al frente. Ni nubes ni tierra. Constata lo que ya sabía: en los aviones no existe horizonte. (Fernández Mallo, 2008: 11)

En la adaptación gráfica de este fragmento, Pere Joan (2011: 8-9) enlaza una serie de viñetas: primero el vuelo de un avión, luego, dentro del mismo avión, el lectoespectador ve a Sandra hojeando una revista. Siguen varios dibujos sin palabras, que muestran el vino Ribeiro, un edificio high-tech, unas joyas Majorica, una playa y, al final, la imagen de la playa en su contexto, el de la revista, sobre la cual cae una gota, o sea una lágrima de los ojos de Sandra, que vuelve a aparecer en la última viñeta. Al construir esta secuencia, Pere Joan decide citar una sola frase de Fernández Mallo - «No por culpa de la playa, ni del Caribe, ni de la gravitación que les es propia a las lágrimas»- antes de mostrar a Sandra mirando por la ventanilla y concluir con la reflexión sobre el horizonte. Cabe destacar que la versión iconográfica de este capítulo es más elíptica, pero que, a pesar de ello, al lectoespectador no le resulta difícil reconstituir el hilo narrativo del texto original. Las frases citadas son más impactantes cuando alternan con dibujos sin palabras.

No obstante, más allá del trabajo de adaptación, se trata de una lectura personal, interpretativa que el dibujante hace de la obra de Agustín Fernández Mallo. Cuando en la novela se vuelve a citar la reflexión sobre el horizonte en uno de los capítulos siguientes - que cuenta la historia de la familia Smith en Irak-, Pere Joan (2011: 20) reproduce la imagen de la joven mirando por la ventanilla del avión, salvo que esta vez ya no se trata de Sandra, sino de una mujer de origen árabe. El dibujante establece así un vínculo directo entre dos fragmentos de texto y entre dos personajes, que el escritor no había expresado en su obra, sobre todo si se tiene en cuenta que la madre de Mohamed Smith no lleva nombre. Pere Joan nota este detalle y decide interpretarlo como un posible paralelo entre las historias de estos dos personajes femeninos. 
36 A partir de este análisis, hay que notar que la novela Nocilla Experience y su versión gráfica constituyen una unidad creativa que ilustra el concepto clave de Vicente Luis Mora, al juntar la doble perspectiva que debe adoptar el lectoespectador, a la vez textual y visual -es decir, textovisual-de esta obra expandida. Los dos medios convierten la lectura en una experiencia compleja, ya que, en la época postdigital, el lector siempre circula entre la página y la pantalla, entre el texto escrito y la representación visual, entre un medio y otro.

Los difuntos (Carrión, 2015a) requiere, a su vez, la misma lectura complementaria, aunque esta vez en el mismo soporte, el del objeto-libro. Las ilustraciones que Celsius Pictor crea para el relato de Jorge Carrión parecen, a primera vista, reproducir visualmente ciertos detalles del texto. Sin embargo, hay que notar que, a través de las figuras iconográficas que acompañan la obra, la lectura se vuelve más compleja $-\mathrm{y}$ completa-. Si algunas imágenes se concentran en el vínculo entre el ser humano y la máquina, como la representación del hotel en forma de elefante -el Elephantine Colossus -, el laboratorio del doctor Dédalo o la Máquina de la memoria, otros dibujos remiten a los diferentes géneros literarios e cinematográficos a los que el autor alude en su relato. El lectoespectador pasa de la historia de atraco (Figura 4; Carrión, 2015a: 53), al western (Figura 5; Carrión, 2015a: 65) e incluso al teatro de marionetas (Figura 8; Carrión, 2015a: 101), que se emplea como técnica de mise en abyme para conocer el desenlace de la historia de Dioniso. De hecho, el propio Carrión llama la atención, en un artículo dedicado a Los difuntos, sobre la importancia de la intergenericidad en la obra: «Escribí Los difuntos porque necesitamos historias, historias de ciencia-ficción, historias de revueltas populares, historias de naufragios y de atracos a bancos y de títeres y de electricidad en el Lejano Oeste.» (Carrión, 2015b) En este contexto, las imágenes son indicios $-o$ sea huellas, para emplear una de las palabras clave de este proyecto narrativo- para el lector.

En Los difuntos, la máquina y la literatura son indisociables, puesto que la máquina es el medio de la literatura (Krzywkowski, 2010) y la literatura es una máquina que produce ficciones, como la máquina de narrar de Ricardo Piglia ${ }^{11}$. En la sección siguiente habrá que detenerse en esta relación entre la creación artística y el dispositivo mecánico en el relato de Jorge Carrión (2015a).

\section{Tecno-visión: intermedialidad del texto y de la máquina. ¿Una revolución tecnológica o estética?}

La última parte del proyecto «Las huellas» se abre con la imagen del conflicto o la tensión entre el ser humano y la máquina:

En posición fetal, el Recién Llegado abre los ojos un segundo antes de ser pisoteado por esa yegua de ancas de acero inoxidable, que no esquiva el obstáculo porque es obligada a seguir en línea recta por su jinete. Sale vapor a presión de sus orificios nasales. Se vuelven rojas las bombillas incandescentes de sus ojos [...]. El dolor detiene el movimiento de las retinas y hace que alargue instintivamente las extremidades, que se hunden en el lodo que lo circunda. Desaparece la yegua de metal y su joven jinete como un tren por el horizonte del progreso, dejando tras ellos el cuerpo triturado de alguien que todavía no es capaz de saber que existe de nuevo. (Carrión, 2015a: 15)

En este incipit se presenta al protagonista - que acaba de materializarse en el mundo de los muertos de la ficción-, pisoteado por la construcción mecánica que sirve de medio 
de transporte en el Nueva York ficcional de Los difuntos, a finales del siglo xIx. Hay un contraste patente entre la fragilidad del cuerpo desnudo y la fuerza de las ancas metálicas del animal, los ojos cerrados del hombre y la incandescencia de las bombillas rojas de la máquina, el lodo que rodea el cuerpo indefenso del Recién Llegado y el progreso técnico que parece dominar la metrópolis estadounidense. En estas primeras líneas de la obra, el ser humano se ve aplastado por el autómata. No obstante, a medida que el relato avanza, se nota la complejidad de las relaciones entre hombre y máquina. A los recién llegados se les explotan como esclavos para alimentar la caldera del hotel en forma de elefante situado en Coney Island. Al mismo tiempo, el propio protagonista recurre a un dispositivo mecánico para recuperar sus recuerdos; se trata de la Máquina de la memoria, capaz de reactivar el pasado de los personajes, la historia que vivieron en el mundo de la ficción del que surgen.

Prosiguiendo la reflexión sobre la relación entre el texto literario y los medios, Los difuntos revela otro significado, que vincula el relato con la historia del cine. Cabe destacar que, según el prólogo, el texto es una rescritura de la serie de televisión City of Machines and Shadows, «el spin-off de The Dead» $»^{12}$ (Carrión, 2015a: 9). Desde el punto de vista temporal, la diégesis que se extiende sobre un lapso bastante largo, desde la última década del siglo XIX hasta la Primera Guerra Mundial. En otras palabras, según esta perspectiva diegética, el marco temporal de la serie coincide con los comienzos del cine. Al optar por este periodo, el autor $-\mathrm{o}$, mejor dicho, el creador de la serie - reconstituye no solo los orígenes de los Nuevos, como protagonistas de Los muertos, sino los orígenes mismos del medio cinematográfico.

Para justificar esta interpretación textual, habrá que analizar el vínculo que se teje entre la Máquina de la memoria, cuya invención se le atribuye, en Los difuntos, a Thomas Edison (Carrión, 2015a: 86), y el Kinetoscopio de Edison, uno de los dispositivos más importantes en la evolución técnica hacia la proyección de imágenes fílmicas. Hay pues una asociación posible entre esta máquina imaginada por Carrión, capaz de reactivar la memoria de los personajes de ficción, y el mecanismo cinematográfico que graba sus historias. Desde este punto de vista, las palabras que enuncia Dioniso -al que llaman también Apolo y Nadie- en el momento en que está conectado a la máquina, pueden interpretarse desde esta perspectiva de la historia cultural y artística:

La mía no fue una muerte física, porque no existía como cuerpo. La mía fue la muerte de un concepto. No fui vida, descubro ahora, fui texto. No tuve rostro, rasgos, fisonomía, sexo, años, huellas dactilares. No tuve límites, porque me tradujeron, de modo que vivo en aquel mundo y en este, en aquel como sucesión de lecturas, como invasión constante en millones de cerebros, en millones de Troyas engañadas por millones de caballos centauros, medio cuerpo de verdad, medio cuerpo de mentira, y en este como errante cuerpo mío que intenta borrar de su mente lo que hizo, caminando y caminando, moviéndose, como si el viaje constante fuera una forma del olvido, como si cada paso sobre el polvo destrozara un recuerdo. (Carrión, 2015a: 94)

La literatura como máquina creadora de ficción adquiere una forma concreta, material en esta obra. Como apunta Krzywkowski,

le choix de la machine ne devient une démarche de création qu'à partir du moment où il ne s'agit pas de prendre un substitut de la plume ou du stylographe, mais d'essayer d'en intégrer et exploiter les spécificités et les nouvelles possibilités, tant dans le champ de l'écriture que dans le processus de création. (Krzywkowski, 2010: 226)

En la época postdigital, el vínculo entre la literatura y su forma material, el texto y el medio es cada vez más fuerte. En el ámbito de la literatura digital, Hayles (2002) califica 
de «tecnotextos» (en inglés, technotexts) las obras en las que se nota el impacto de la tecnología en la construcción del texto, puesto que, como apunta la autora, la forma física o las propiedades materiales del artefacto literario afectan invariablemente su significado ${ }^{13}$. La obra postdigital integra técnicas narrativas como el tecnotexto para poner en tela de juicio la tecnología misma que la produce o que le sirve de medio.

De la pantpágina al tecnotexto, la obra literaria mutante muestra pues que la interacción entre la escritura y los medios es la condición sine qua non del proceso creativo en la época contemporánea.

\section{Conclusiones}

$\mathrm{Al}$ interactuar con los medios, la obra mutante se deja transformar y, al mismo tiempo, también modifica la función mediática de los dispositivos tecnológicos en función narrativa o artística. En otras palabras, la obra mutante surge de este encuentro entre la escritura literaria, las artes y los medios que las diseminan. En la época postdigital, la literatura expandida elige invertir en su capacidad dialógica con las artes y los medios, al integrar otros lenguajes en su tejido textual.

Por consiguiente, en el siglo xxI se produce un cambio de perspectiva sobre la relación entre el texto y la imagen en particular. El concepto mismo de postdigitalidad indica, por un lado, que el lenguaje binario ha integrado los modos de creación y expresión artística como herramienta común y, por otro lado, que los autores adoptan una posición crítica en cuanto a las diferentes funciones de tales dispositivos.

Tanto en el proyecto «Nocilla» de Agustín Fernández Mallo como en el relato Los difuntos de Jorge Carrión, la intersección de dos lenguajes disímiles engendra un proceso de intersemiotización, mediante el cual cada medio adquiere un significado nuevo. En Nocilla Lab, las fotos de la pantalla del televisor intensifican la experiencia de aislamiento y encierro del narrador en la pensión-penitenciaría. A través de estas representaciones iconográficas, hay un enfoque sobre la necesidad de convertir al telespectador, a menudo pasivo frente a superabundancia de imágenes a la que está sometido, en lectoespectador capaz de asumir una visión crítica e interpretar el contenido textovisual que lo asalta diariamente.

También la adaptación gráfica de Nocilla Experience y las ilustraciones de Los difuntos recalcan el papel hermenéutico de la imagen. Las dos versiones de Nocilla Experience son complementarias, puesto que la novela gráfica propone una lectura alternativa del texto de Agustín Fernández Mallo. Las figuras de Celsius Pictor en el relato de Carrión invitan, a su vez, a una interpretación-intergenérica-del texto. Así pues, cabe destacar que el trabajo colaborativo entre el escritor y el dibujante suscita, en estas obras mutantes, una doble lectura, del texto y de la imagen, es decir una experiencia textovisual.

El relato Los difuntos subraya asimismo que la creación artística mantiene una relación estrecha con la tecnología. La imagen -fotográfica o fílmica- es un arte que emerge y florece a través del desarrollo técnico del dispositivo. La máquina -tanto del cine como de la memoria-es un elemento central de este texto que cierra el proyecto «Las huellas», al servir de soporte técnico para el arte cinematográfico y de herramienta narrativa para el arte literario. 
51 Al situarse en este espacio indefinido entre los medios, la obra postdigital se define por su tejido intermedial. Las obras narrativas que he analizado en este artículo subrayan la importancia del vínculo entre la escritura y el dispositivo mediático, como tendencia ineludible en la época contemporánea. Al emplear el lenguaje visual, los escritores mutantes Jorge Carrión y Agustín Fernández Mallo cuestionan los medios de representación actuales e invitan, de esta manera, a volver a pensar qué significa escribir -y cómo hacerlo- hoy en día. Las herramientas tecnológicas forman parte de esos objetos del mundo real que, al emplearse en el proceso de creación, se convierten en dispositivos de expresión artística. En la poética mutante, el objeto mediático es parte constitutiva de la obra.

En el siglo XXI, la escritura intermedial supone desarrollar una dinámica creativa híbrida, situarse en el territorio indefinido entre distintos medios para poder mediar entre la literatura y el mundo. La narrativa mutante ocupa esta zona fronteriza, borrosa, para poder desarrollar una nueva estética, postdigital, que alimenta su potencial artístico a partir de la tensión entre los medios, entre el texto y la imagen.

\section{BIBLIOGRAFÍA}

BOUCHARDON Serge (2014), La Valeur heuristique de la littérature numérique, París: Hermann.

CARRIón Jorge (2015a), Los difuntos (Celsius Pictor, ilust.), Badajoz: Aristas Martínez.

CARRIÓN Jorge (2015b), «¿Por qué escribí Los difuntos?», en línea en Pliego Suelto: <http://

www.pliegosuelto.com/?p=17719> (29 de junio de 2017).

CRAMER Florian (2016), «Post-Digital Literary Studies», Materialidades da Literatura, 4(1), 11-27.

DENA Christy (2009), Transmedia Practice: Theorising the Practice of Expressing a Fictional World across Distinct Media and Environments (tesis de doctorado), Universidad de Sydney, Australia, <http:// ciret-transdisciplinarity.org/biblio/biblio_pdf/Christy_DeanTransm.pdf> (29 de junio de 2017). FERNÁNDEZ MALlo Agustín (2004), «Hacia un nuevo paradigma: Poesía Postpoética», Lateral, 120. FERNÁNDEZ MALLO Agustín (2008), Nocilla Experience, Madrid: Alfaguara.

FERNÁNDEZ MALlo Agustín (2009), Nocilla Lab, Madrid: Alfaguara.

FERNÁNDEZ MALLo Agustín (2014), Limbo, Madrid: Alfaguara.

FISCHER Caroline (2015), «Intermedia et intermédialité», C. Fischer (dir.), Intermédialités, París: Lucie Éditions, 7-18.

FOSTER WALLACE David (2014), A Supposedly Fun Thing I'll Never Do Again [1997], Londres: Abacus.

HAYLES Katherine N. (2002), Writing Machines, Cambridge (Mass.), Londres: MIT Press.

JENKINS Henry (2007), «Transmedia 101», en línea en Confessions of an Aca-Fan: <http://

henryjenkins.org/2007/03/transmedia_storytelling_101.html> (29 de junio de 2017). 
JENKINS Henry (2008), Convergence Culture. La cultura de la convergencia de los medios de comunicación [2006] (P. Hemida Lazcano, trad.), Barcelona: Paidós Ibérica.

JENKINS Henry (2011), «Transmedia 202: Further Reflections», en línea en Confessions of an Aca-Fan: <http://henryjenkins.org/2011/08/defining_transmedia_further_re.html> (29 de junio de 2017). JOAN Pere (2011), Nocilla Experience. La novela gráfica, Madrid: Alfaguara.

KRZYWKOWSKI Isabelle (2010), Machines à écrire. Littérature et technologies du XIXe au XXI siècle, Grenoble: ELLUG.

MANOVICH Lev (2010), Le Langage des nouveaux médias [2001] (R. Crevier, trad.), Dijon: Les presses du réel.

MORA Vicente Luis (2012), Lectoespectador: deslizamientos entre literatura e imagen, Barcelona: Seix Barral.

PANTEL Alice (2012), Mutations contemporaines du roman espagnol : Agustín Fernández Mallo et Vincente Luis Mora (tesis de doctorado), Université Paul Valéry Montpellier 3, Montpellier, <https:// tel.archives-ouvertes.fr/tel-00824207> (29 de junio de 2017).

SIERRA Germán (2010), «Bienvenidos a la era postdigital», Quimera, 314, 10.

SIERRA Germán (2012), «Post-Digitalism and Contemporary Spanish Fiction», C. Henseler \& D. A. Castillo (dir.), Hispanic Issue On Line, 9, 22-37.

VIERKANT Artie (2010), The Image Object Post-Internet, en línea en <http://jstchillin.org/artie/ vierkant.html> (29 de junio de 2017).

vouilLoux Bernard (2015), «Intermédialité et interaticité. Une révision critique», C. Fischer (dir.), Intermédialités, Paris: Lucie Éditions, 55-69.

\section{NOTAS}

1. El lectoespectador es «cualquier tipo de receptor de manifestaciones artísticas textovisuales que realiza un ejercicio cotidiano de cibercepción en el que se expanden las posibilidades de flujo informativo y de sentido entre dichas manifestaciones y la realidad pangeica» (Mora, 2012: 19). Por «cibercepción», concepto acuñado por Roy Ascott, el autor entiende la adopción de una «perspectiva sobre el conjunto, a vista de pájaro» (Mora, 2012: 18), es decir una visión unitaria de la obra diseminada en varias plataformas.

2. Hay que indicar que Alice Pantel (2012) propone una noción similar, la de «novela aumentada» (roman augmenté) para describir la expansión de la obra más allá de los límites del libro impreso. De hecho, el propio Agustín Fernández Mallo alude, en su artículo sobre la teoría de la postpoesía (Fernández Mallo, 2004), al concepto de "poesía expandida», con el fin de identificar la creación lírica que fomenta la interacción con las nuevas tecnologías. El propio autor se inspira del ámbito cinematográfico, donde se habla de "cine expandido» para designar las películas que emplean efectos especiales (o sea la tecnología) u otros medios, como el video, en el proceso de creación artística. En el prólogo al trabajo de Lev Manovich (2010 [2001]) sobre la relación entre el cine y los medios digitales, Yann Beauvais aclara que en los años 1970 Gene Youngblood acuña la expresión «cine expandido» para referirse a la presencia de otros medios en el cine, por ejemplo, la transmisión en directo o el happening (Manovich, 2010 [2001]: 16).

3. Citado por Vouilloux (2015: 55).

4. No hay que olvidar que, ya en los años 1990, en un artículo que estudia el impacto de la televisión sobre la concepción de la realidad, el escritor estadounidense David Foster Wallace 
habla de una nueva narrativa, que él llama Image-Fiction. Según apunta el autor, esta práctica literaria no se contenta con evocar simplemente la televisión, sino que cuestiona el medio y sus consecuencias tanto sobre la sociedad como sobre la literatura (Foster Wallace, 2014 [1997]: 43).

5. La noción de escritura adquiere aquí, según el estudio de Bouchardon, un significado puramente técnico: se trata de ficheros que los informáticos escriben en lenguajes diferentes (Bouchardon, 2014: 53).

6. Como se apunta en la nota que acompaña este mapa, se trata de una adaptación del sistema de representación «cosmos:n», cuyo autor es Javier Cañada. Para obtener más detalles sobre el proyecto, se puede consultar su página web: <http://www.terremoto.net>.

7. En cuanto a eso, hay que mencionar también Crónica de viaje (2014), cuya forma singular es el resultado del trabajo de la editorial Aristas Martínez, y Barcelona. Los vagabundos de la chatarra (Norma, 2015), que Carrión concibe con el dibujante Sagar Fornies. Se trata de un trabajo híbrido que presenta el proceso de investigación periodística del autor en forma de cómic.

8. No hay que olvidar que, en el mismo periodo, en el área de las ciencias de la comunicación, Lev Manovich (2001) estudia lo que llama la estética post-media o informacional. Para el autor, el post-media supone el uso tanto de los medios tradicionales como de los nuevos medios, como forma de representación del mundo.

9. Por ejemplo, el proyecto fílmico «Narrar América», disponible en la bitácora del autor, «El hombre que salió de la tarta» o el proyecto apropiacionista El hacedor (de Borges). Remake (Alfaguara, 2011), que consiste en un libro, al que se le añaden varios videos en YouTube.

10. Cabe mencionar que una de las fotos que aparecen en esta secuencia visual se emplea también en otra obra del autor, Limbo, que se publicará cinco años más tarde: «Se trata de una fotografía proveniente de un spot publicitario, que alguien había hecho a su pantalla de televisor.» (Fernández Mallo, 2014: 83) La intertextualidad es explícita: la persona que ha hecho la foto es el protagonista de Nocilla Lab. La imagen adquiere, sin embargo, otro significado, según el contexto en que se emplea. Si, en Nocilla Lab, la imagen recalca en el aislamiento del personaje, en Limbo, la misma imagen se introduce en una secuencia fotográfica en la que el número de seres humanos aumenta de una imagen a otra e ilustra así la evolución desde la solitud a la constitución de una comunidad (Fernández Mallo, 2014: 85).

11. Se trata de la Máquina de Macedonio, que se describe en su obra La ciudad ausente (Mondadori, 1992).

12. The Dead es la producción de la cadena Fox que constituye el eje narrativo de la primera parte del proyecto «Las huellas», la novela Los muertos (Mondadori, 2010).

13. Hayles explica que: «Not all literary works make this move, of course, but even for those that do not, my claim is that the physical form of the literary artifact always affects what the words (and other semiotic components) mean. Literary works that strengthen, foreground, and thematize the connections between themselves as material artifacts and the imaginative realm of verbal/semiotic signifiers they instantiate open a window on the larger connections that unite literature as a verbal art to its material forms. To name such works, I propose "technotexts", a term that connects the technology that produces texts to the texts' verbal constructions. Technotexts play a special role in transforming literary criticism into a material practice, for they make vividly clear that the issue at stake is nothing less than a full-bodied understanding of literature.» (Hayles, 2002: 25-26) 


\section{RESÚMENES}

El objetivo de este artículo es analizar, a partir de las obras Los difuntos de Jorge Carrión, Nocilla Experience y Nocilla Lab de Agustín Fernández Mallo, diferentes prácticas intermediales en la narrativa mutante a principios del siglo xxI. En este contexto, hay que enfocar los diferentes usos de la imagen en el texto literario, que pueden variar de la manipulación digital de la fotografía por el autor a la elaboración de proyectos colaborativos con otros artistas. Los ejemplos literarios estudiados indican que la hibridación mediática es uno de los ejes de la estética postdigital.

L'objet de cet article est d'étudier, à partir des ouvrages Los difuntos de Jorge Carrión, Nocilla Experience et Nocilla Lab d'Agustín Fernández Mallo, plusieurs pratiques intermédiales dans les œuvres narratives mutantes au début $d u \mathrm{xxI}^{\mathrm{e}}$ siècle. Dans ce contexte, une attention particulière est donnée à la présence de l'image dans le texte littéraire, image qui peut prendre diverses formes: de la manipulation numérique opérée par l'auteur lui-même sur la photographie à l'élaboration de projets collaboratifs avec d'autres artistes. Les exemples littéraires analysés ici montrent que l'hybridation médiatique est une technique essentielle dans l'esthétique postnumérique.

This article focuses on certain literary works, such as Jorge Carrión's short-story Los difuntos and Agustín Fernández Mallo's novels Nocilla Experience y Nocilla Lab, in order to observe some of the most significant intermedial practices in the mutant narrative published at the beginning of the $21^{\text {st }}$ century. Within this framework, I will delve in the various uses of the image in the literary text, from the digital manipulation of photos performed by the author himself, to the creation of collaborative projects with other artists. The literary samples studied in this article indicate that media hybridisation is one of the main techniques of postdigital aesthetics.

\section{ÍNDICE}

Mots-clés: intermédialité, hybridation médiatique, littérature en expansion, esthétique postnumérique, Jorge Carrión, Agustín Fernández Mallo

Palabras claves: intermedialidad, hibridación mediática, literatura expandida, estética postdigital, Jorge Carrión, Agustín Fernández Mallo

Keywords: intermediality, media hybridisation, expanded literature, postdigital aesthetics, Jorge Carrión, Agustín Fernández Mallo

\section{AUTOR}

\section{ROXANA ILASCA}

ILCEA4 - Université Grenoble Alpes 